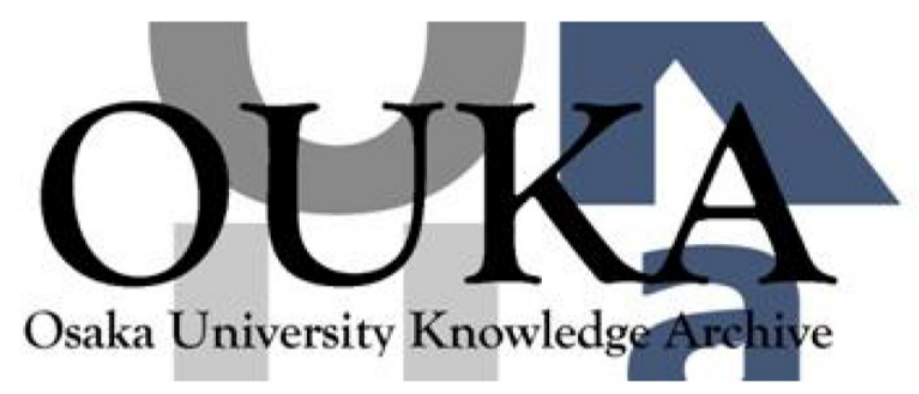

\begin{tabular}{|c|l|}
\hline Title & $\begin{array}{l}\text { Hybrid system for in-situ observation of } \\
\text { microstructure evolution in steel materials }\end{array}$ \\
\hline Author(s) & $\begin{array}{l}\text { Komizo, Yu-ichi; Terasaki, Hidenori; Zhang, } \\
\text { Xinfang }\end{array}$ \\
\hline Citation & Transactions of JWRI. 41(2) p.39-p. 46 \\
\hline Issue Date & $2012-12$ \\
\hline oaire:version VoR \\
\hline URL & https://doi.org/10.18910/24858 \\
\hline rights & \\
\hline Note & \\
\hline
\end{tabular}

Osaka University Knowledge Archive : OUKA

https://ir. Library. osaka-u. ac. jp/

Osaka University 


\title{
Hybrid system for in-situ observation of microstructure evolution in steel materials ${ }^{\dagger}$
}

\author{
KOMIZO Yu-ichi *, TERASAKI Hidenori **, ZHANG Xinfang ***
}

\begin{abstract}
A new technique, based on the combination of time-resolved X-ray diffraction (TRXRD) and high-temperature laser scanning confocal microscopy (LSCM), was developed for direct observation of morphological evolution and simultaneous identification of the phases. TRXRD data and LSCM images under the desired thermal cycles were measured simultaneously. In several observation examples, the microstructural evolutions in the steel materials were observed to investigate the phase transformation kinetics under the thermal cycle of rapid heating and cooling.
\end{abstract}

KEY WORDS: (synchrotron), (TRXRD), (X-ray), (phase transformation), (welding), (laser scanning confocal microscopy (LSCM)), (in-situ), (microstructure)

\section{Introduction}

Over the past decade, two synchrotron based techniques have been developed at Lawrence Livermore National Laboratory for direct observation of phase transformations induced by welding. These techniques are spatially resolved X-ray diffraction (SRXRD), which was developed to map the phases that exist in the HAZ 1-6), and time-resolved X-ray diffraction (TRXRD).

Elmer et al. ${ }^{7-12)}$ showed that TRXRD could track phase transformation during welding in real time. Synchrotron radiation makes time-resolved diffraction measurements possible in local areas; phases that exist in the HAZ and fusion zone (FZ) of metal can be identified in real time. This technique was used to analyse the phase transformation during solidification of carbon-manganese (C-Mn) steel, and Babu et al. ${ }^{10)}$ verified the existence of non-equilibrium phases directly in the rapid cooling cycle of spot welds. In addition, TRXRD can be applied in tracking the phase evolution in the HAZ. The formation of the microstructures of duplex stainless steel (DSS) ${ }^{11)}$ and $\mathrm{C}-\mathrm{Mn}{ }^{8)}$ steel were observed in the thermal cycle of HAZ using TRXRD system. In experiments with DSS, the phase balance between ferrite and austenite was estimated, and the precipitation of the detrimental phase in the thermal cycle of the HAZ was assessed. In TRXRD experiments with C-Mn steel, the effect of transformation strain on the diffraction pattern profile during martensitic transformation was discussed.

Our research group began TRXRD experiments for welding by developing a new technology for the system

\footnotetext{
$\dagger$ Received on December 17, 2012

* Professor

** Assistant Professor

*** Specially Appointed Researcher
}

13-26). We focussed on the details of the weld solidification phenomena in the directional solidification process under rapid cooling because the influence of a preferred orientation was important for observing directional solidification along the $\langle 100\rangle$ direction towards the moving heat source. First, the solidification process was confirmed by SRXRD as a function of the distance from the weld pool, which was melted by an arc of the quenched metals after welding ${ }^{13,14)}$. However, the observation of crystallization at a lateral resolution in relation to a time resolution of $0.1 \mathrm{~s}$ was impossible. That is, because the microstructure was ultimately static, understanding the crystallography during heating and cooling was not possible. For instance, the eutectic microstructure is formed in the liquid phase during solidification; the displacement of interplanar spacing by thermal expansion and shrinkage could not be observed. Next, the phase transformation was dynamically observed along a certain direction on the reciprocal space using an imaging plate ${ }^{15-17)}$. A crystallinity change was observed with a temperature drop, and the growth of dendrites was captured. We assumed the rotation of dendrites from the discontinuous diffraction pattern recorded by the imaging plates along one direction of reciprocal space. However, eutectic growth in the remaining liquid phase was confirmed, though peritectic growth of the hetero phase on the primary phase was expected. Therefore, it was difficult to simultaneously observe the primary phase and the hetero phase along a certain direction because interfaces have coherency and preferred crystal

Transactions of JWRI is published by Joining and Welding Research Institute, Osaka University, Ibaraki, Osaka 567-0047, Japan 


\section{Hybrid system for in-situ observation of microstructure evolution in steel materials}

orientation.

With the availability of intense X-ray beams from synchrotron storage rings, it is now possible to directly observe phase transformation and microstructural evolution in situ and in real time as a function of welding time. Therefore, we developed a two-dimensional time-resolved X-ray Diffraction (2D-TRXRD) system for real welding ${ }^{18-28)}$. Weld metal rapid solidification was then dynamically observed at a time resolution of $0.01-0.1 \mathrm{~s}$.

The monochromatic X-ray is used as a probe with the incident beam from one direction in the study described above. Detecting a wider area of the Debye circle is very important. For analysing the solidification process, the weak and broad halo pattern is a clear sign of the existence of liquid. Thus, detecting halo patterns with a high $\mathrm{S} / \mathrm{N}$ ratio detector indicates the beginning and the end of solidification ${ }^{25)}$.

Further, a combination of analyses methods (the in situ phase identification system, morphological observation by high-temperature laser scanning confocal microscopy (LSCM) and observation of the microstructure at room temperature with an optical microscope, scanning electron microscope and micro diffraction system) was suggested for analysing the phase transformation during welding ${ }^{20-22,24-30)}$.

The TRXRD data obtained during welding needs to be combined with the appropriate temperature history to obtain the phase transformation kinetic data. The LSCM technique can give us information such as the morphological development of microstructures and precise temperature ${ }^{31,32)}$.

Then a new technique based on the TRXRD and LSCM system was developed in the present study. In some observation examples, the microstructural evolutions in the steel materials were observed to investigate the phase transformation kinetics under the thermal cycle of rapid heating and cooling.

\section{Hybrid system for in situ observation in real and reciprocal lattice space \\ 2.1 Overview of system}

Figure 1 shows a photograph of the experimental setup on the $46 \mathrm{XU}$ beam line at SPring-8 in Hyogo, Japan. The infrared furnace was set on the theta-axis of a goniometer situated within the hatch of the beam line. In this system, the head of the laser scanning confocal microscope (LSCM) was also set by fitting the theta-axis, as shown in the photograph. The focus point of the LSCM is on the surface of the observed sample which is set in the furnace. A two-dimensional pixel detector was placed on the two-theta axis. The incident beam, i.e., an ultra bright X-ray, was introduced to the furnace and the diffractions were recorded by the pixel detector with high time resolution. Simultaneously, the microstructural changes were observed through the LSCM in situ.

\subsection{Detailed experimental procedures}

Figure 2 shows a schematic illustration of the control

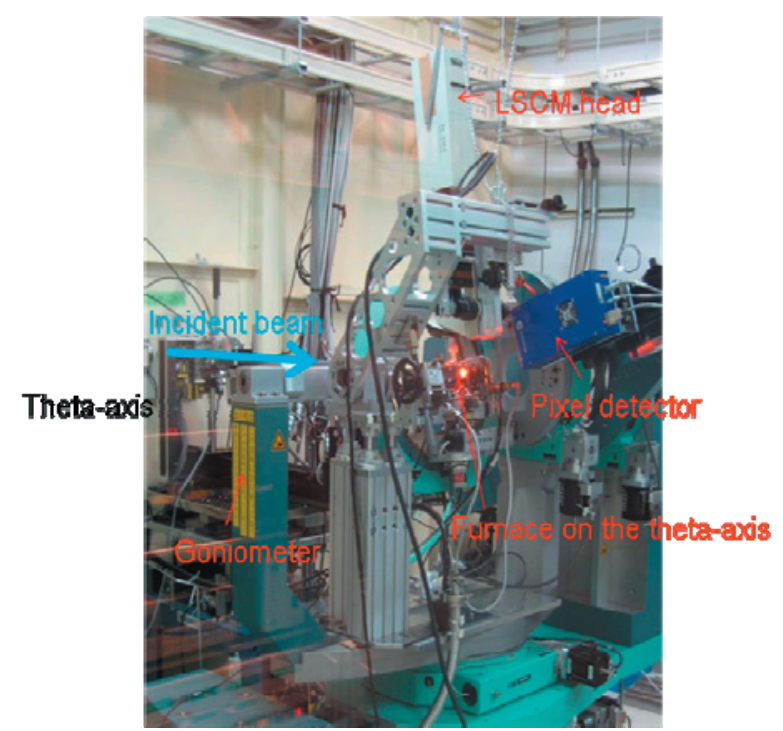

Fig.1 Photograph of the experimental setup at the 46XU beam-line at SPring-8 in Hyogo, Japan

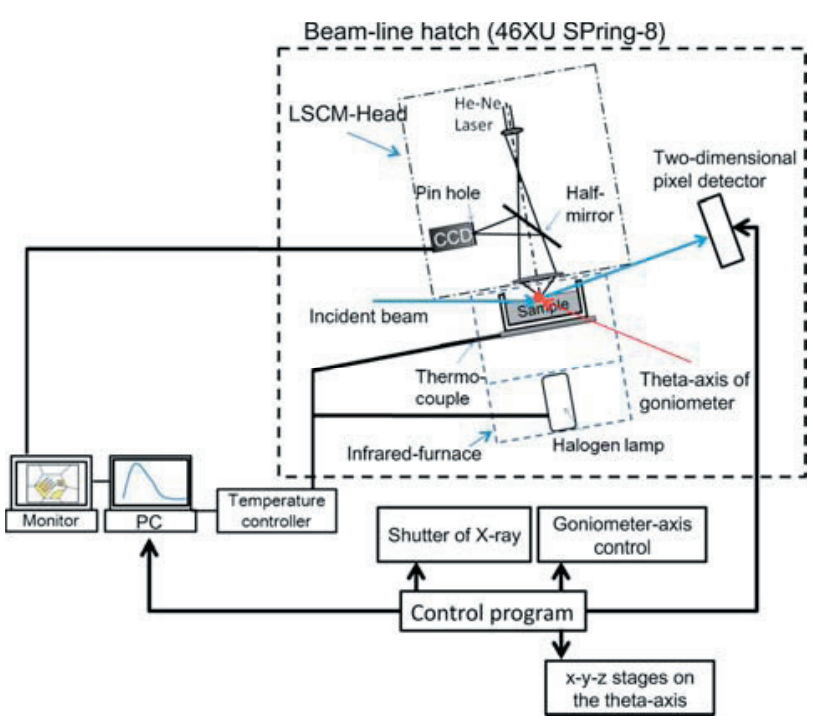

Fig.2 Hybrid in-situ observation system in real and reciprocal lattice space ${ }^{31)}$

flow for the experiment of in situ observations in real and reciprocal lattice space. The specimens, $5 \mathrm{~mm}$ in diameter and $1 \mathrm{~mm}$ thick, were place in the boron-nitride $(\mathrm{BN})$ crucible in which the X-ray absorption is quite small, and held in a platinum holder, which was inserted in the furnace. The temperature was measured by a thermocouple incorporated into the crucible holder. The specimens were placed at the focal point of the halogen lamp. The temperature controller, which was connected to a personal computer (PC), the thermocouple and the halogen lamp in the furnace were placed outside of the beam line hatch. When the thermal cycles that simulate welding were developed on the PC, the profiles were sent to the temperature controller, which reproduced the desired thermal cycles by switching the halogen lamp on and off, based on the measured temperature. The LSCM head makes it possible to carry out in situ observations of 
microstructural changes at a rate of 30 frames/s, at high temperature ${ }^{21,22,27)}$. A CCD camera was connected to the PC located outside the hatch through the monitor, and the images were stored at a rate of 30 frames/s. The control program could trigger the temperature controller, the $\mathrm{X}$-ray shutter, the $\mathrm{x}-\mathrm{y}-\mathrm{z}$ stages on $\theta$-axis, goniometer-axis control and the exposure of the pixel detector.

Before the measurements, the specimen position was adjusted in the manner explained in the following section. Then, the $\theta$-axis was tilted to a fixed angle $\left(10^{\circ}\right.$ in the present study). The temperature controller was then triggered at a set timing and, the exposure of the detector was activated with the time resolution of $0.2 \mathrm{~s}$. TRXRD data and LSCM images under the desired thermal cycles were measured simultaneously.

\subsection{Scattering geometry of X-rays in the experimental setup}

Figure 3 shows the scattering geometry of the TRXRD part of system. The undulator beam was monochromatized by the double Si-crystal, and $30 \mathrm{keV}$ of $\mathrm{X}$-ray energy was used. The X-ray was introduced into the hatch through a mirror-the incident beam shown in Figs. 1 and 2. The X-ray was shaped by the slit. In the present study, the beam is shaped into dimensions of 0.5 $\mathrm{mm}$ height and width. The X-ray beam was introduced into the furnace through an X-ray window made with film. Before the measurements, the position of the sample surface was adjusted. By controlling the z-stage, the sample surface is forced to be at the half position of the beam height as indicated by the dashed line in Fig. 3 the $\theta$-axis was then rotated to the angle of $10^{\circ}$ in the present study. The resulting irradiated area was $1.4397 \mathrm{~mm}^{2}$. The penetration depth is derived using Eq. (1) ${ }^{33)}$ :

$\int_{0}^{t} \frac{I_{0}}{\sin \gamma} e^{-\mu x(1 / \sin \gamma+1 / \sin \beta)} d x=G \cdot \int_{0}^{\infty} \frac{I_{0}}{\sin \gamma} e^{-\mu x(1 / \sin \gamma+1 / \sin \beta)} d x$

Where $I_{0}$ is the intensity of the incident beam, $\gamma$ is the angle between the incident beam and the sample surface and $\beta$ is the angle between the diffracted beam and sample surface.

\section{Thermal stability of carbides and carbonitrides during thermal cycle}

Precipitation reactions of heat-resistant steel occurring during welding, both growth and coarsening of existing phases and the formation of new phases, can be detrimental for creep strength. However, understanding of the thermal stability of precipitates during the heat cycle of welding is insufficient. In this study, an attempt has been made to investigate the possibility of analyzing carbides/carbonitrides stability occurring in the heat affected zone based on in situ time-resolved X-ray diffraction using a synchrotron.

In this study, two types of heat-resistant steels were selected for study, ferritic steel and austenitic steel. The chemical compositions of the steels ware listed in Table 1. Then the in situ observation was carried out using the

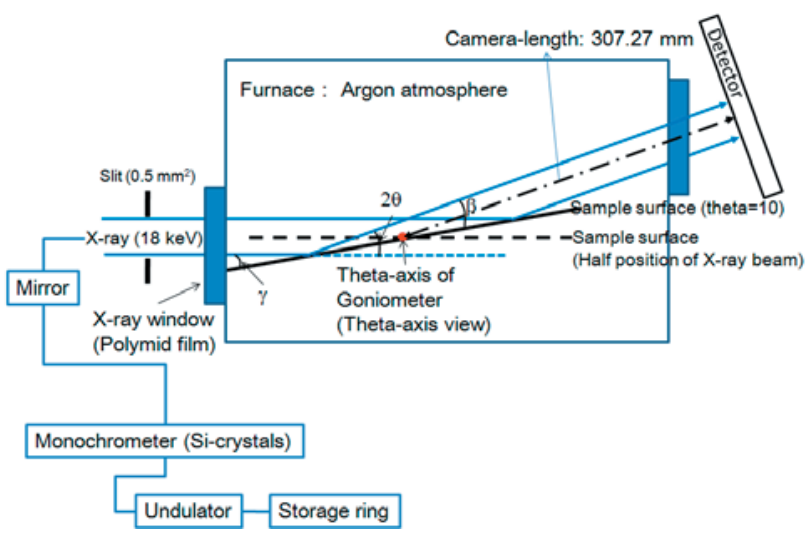

Fig.3 Scattering geometry of X-rays in the experimental setup

hybrid observation system.

Figure 4a ${ }^{34)}$ displays both the TRXRD and the corresponding temperature data obtained during the continuous heating and cooling of the investigated steel at heating and cooling rates of $8.3^{\circ} \mathrm{C} \mathrm{s}^{-1}$. The temperatures and times at which certain phases are present during the heat treatment can be obtained from these plots. Figure 4b shows selected X-ray diffractograms of experimental steel corresponding to Figure $4 \mathrm{a}$. In the case of the heating process, the diffraction patterns do not exhibit significant changes in the range of temperate from 24 to $1365.5^{\circ} \mathrm{C}$. However, the diffraction intensity of the e- $\mathrm{Nb}(\mathrm{C}, \mathrm{N})$ decreased sharply at $1365.5^{\circ} \mathrm{C}$, indicating that dissolution in the precipitates is occurring under the thermodynamic driving force. The diffraction intensity of the $\mathrm{e}-\mathrm{Nb}(\mathrm{C}, \mathrm{N})$ continued to decrease until it had completely disappeared at $1372.5^{\circ} \mathrm{C}$. At the same temperature, the $\mathrm{d}-\mathrm{Nb}(\mathrm{C}, \mathrm{N})$ just begins to dissolve, corresponding to the reduction of its diffraction intensity. This indicates that the dissolution of the $\mathrm{d}-\mathrm{Nb}(\mathrm{C}, \mathrm{N})$ begins at a higher temperature $\left(1372.5^{\circ} \mathrm{C}\right)$ than the $1365.5^{\circ} \mathrm{C}$ of the e-Nb(C,N). Finally, only weak $\mathrm{d}-\mathrm{Nb}(\mathrm{C}, \mathrm{N})$ diffraction peaks could be detected when the temperature dropped to $1148.3^{\circ} \mathrm{C}$. This indicates that the $\mathrm{d}-\mathrm{Nb}(\mathrm{C}, \mathrm{N})$ is just starting to re-precipitate in the austenite. The re-precipitation was completed at $1115.5^{\circ} \mathrm{C}$. Moreover, according to the weak diffraction intensity, there should only be a small amount of reprecipitation in the austenite.

Figure $5^{34)}$ shows the progression of the measured $\delta$ - $\mathrm{Nb}(\mathrm{C}, \mathrm{N})\left(\begin{array}{lll}1 & 1 & 1\end{array}\right)$ and $\varepsilon-\mathrm{Nb}(\mathrm{C}, \mathrm{N})\left(\begin{array}{lll}1 & 0 & 2\end{array}\right) \mathrm{d}$-spacing values of austenitic steel as a function of temperature. In the initial stages of the experiment, the d-spacing values of $\delta-\mathrm{Nb}(\mathrm{C}, \mathrm{N})$ and $\varepsilon-\mathrm{Nb}(\mathrm{C}, \mathrm{N})$ display the steady increase which generally corresponds to lattice expansion due to increasing temperature. After the temperature of $1274^{\circ} \mathrm{C}$,

Table 1 Chemical compositions of the studied steel (in mass \%) with balance of $\mathrm{Fe}$

\begin{tabular}{ccccccccccccc}
\hline$/$ & $\mathrm{C}$ & $\mathrm{Si}$ & $\mathrm{Mn}$ & $\mathrm{Cr}$ & $\mathrm{Ni}$ & $\mathrm{Nb}$ & $\mathrm{N}$ & $\mathrm{Co}$ & $\mathrm{Mo}$ & $\mathrm{V}$ & $\mathrm{w}$ & $\mathrm{B}$ \\
\hline Austenitic & 0.06 & 0.4 & 1.2 & 20 & 20 & 2 & 0.25 & $/$ & $/$ & $/$ & $/$ & $/$ \\
Ferritic & 0.12 & 0.15 & 0.5 & 10 & 0.5 & 0.16 & 0.03 & 2.5 & 0.5 & 0.2 & 2 & 0.005 \\
\hline
\end{tabular}




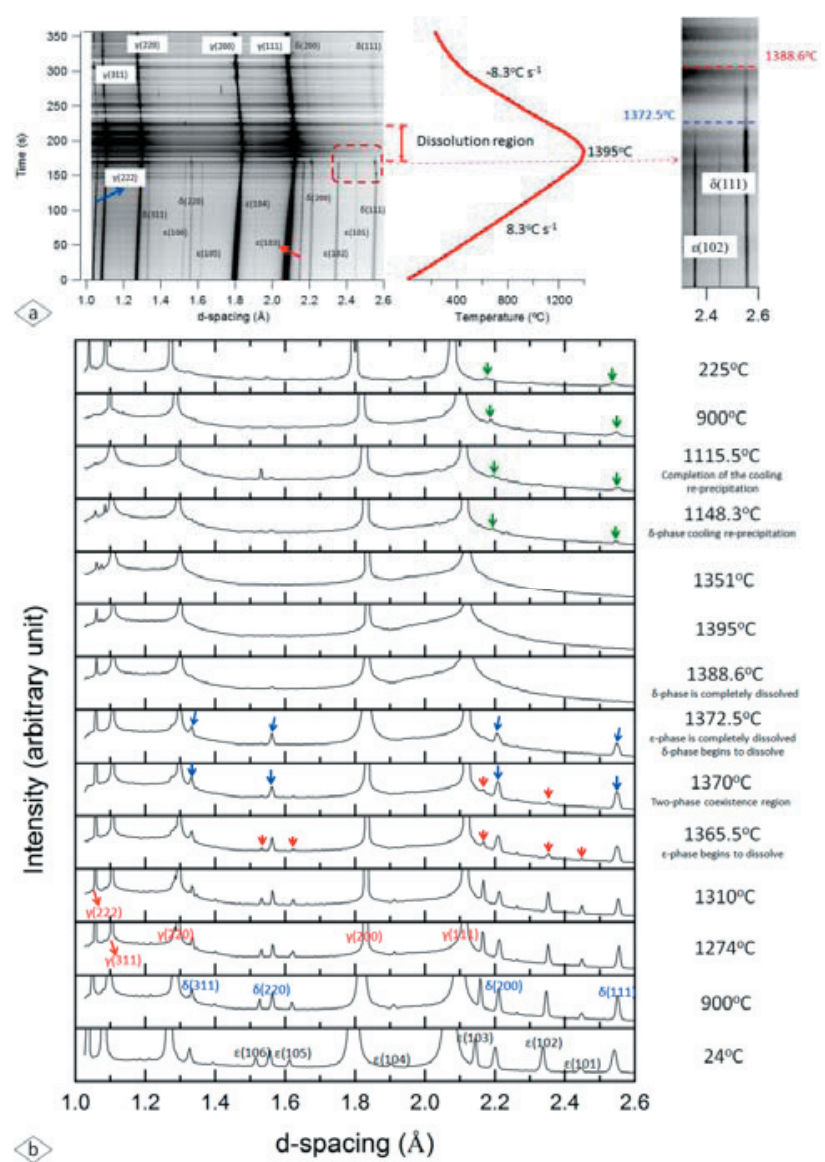

Fig.4 (a) Changes in diffraction patterns and lattice parameter of investigated steel during the heating and cooling process (b) Selected X-ray diffractograms of experimental steel corresponding to $(\mathrm{a})^{34)}$

which are indicated on the plot by the arrows, the d-spacing of $\delta$ - $\mathrm{Nb}(\mathrm{C}, \mathrm{N})$ exhibits a sharp decrease during continuous heating when an expansion is expected, indicating that changes in the $\delta-\mathrm{Nb}(\mathrm{C}, \mathrm{N})$ precipitates are occurring before the dissolution. The contraction of $\delta-\mathrm{Nb}(\mathrm{C}, \mathrm{N})$ carbonitrides might be related with covalent bonding energy. According to the electronic structure of niobium carbonitrides, the covalent bonds $\mathrm{Nb}-\mathrm{N}$ and $\mathrm{Nb}-\mathrm{C}$ are formed by $\mathrm{p}-\mathrm{d}$ hybridization, which determines its thermodynamic stability. Once the $\mathrm{Nb}-\mathrm{N}$ or $\mathrm{Nb}-\mathrm{C}$ covalent bonds are destroyed with heat before the dissolution, $\mathrm{N}$ and $\mathrm{C}$ atoms will dissolve from the interstitial sites of niobium carbonitrides. Thus, the contraction of $\delta-\mathrm{Nb}(\mathrm{C}, \mathrm{N})$ will be present in the form of d-spacing decrease. With the further increase of temperature, more and more $\mathrm{Nb}-\mathrm{N}$ and $\mathrm{Nb}-\mathrm{C}$ covalent bonds will be broken, which leads to a further contraction of the lattice. This seems to indicate that $\delta-\mathrm{Nb}(\mathrm{C}, \mathrm{N})$ particles are not thermodynamically stable during the coarsening process. Until the $\mathrm{Nb}-\mathrm{N}$ and $\mathrm{Nb}-\mathrm{C}$ covalent bonds are totally destroyed, $\delta$-phase particles will be completely dissolved into austenite. But the d-spacing of the $\varepsilon-\mathrm{Nb}(\mathrm{C}, \mathrm{N})$ exhibits a continued increase along with the increasing temperature. It is likely that the hexagonal

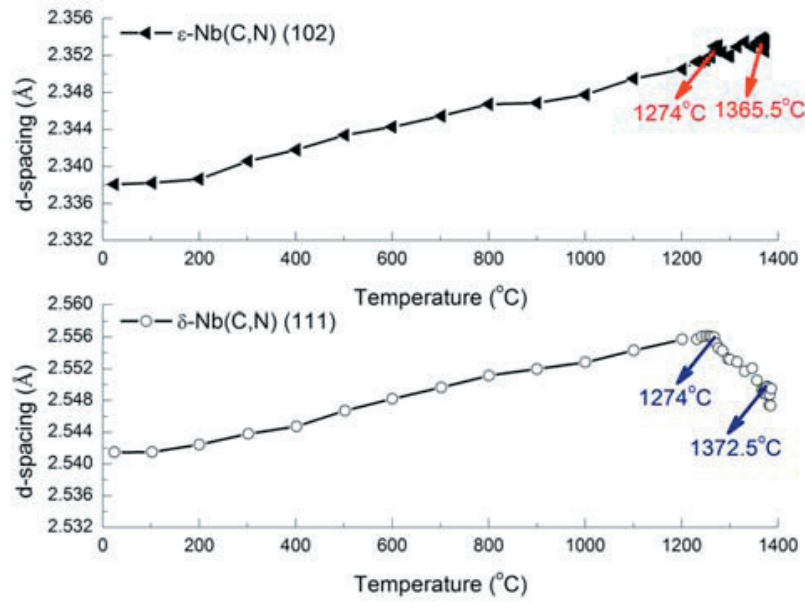

Fig.5 Changes in $d$-spacing of $\varepsilon-\mathrm{NbN}\left(\begin{array}{lll}1 & 0 & 2\end{array}\right)$ and $\delta$-NbN (111) for heating rate $8.3^{\circ} \mathrm{C} \mathrm{s}^{-1}$ as function of temperature. Arrows on plot indicate the initiation of the niobium carbonitrides coarsening and dissolution, respectively ${ }^{34)}$

$\varepsilon$-phases possess a larger covalent contribution to the chemical bonding than the cubic one, which may give rise to higher thermodynamic stability as discussed above.

Figure $6^{35)}$ exhibits the progression of the measured $\mathrm{M}_{23} \mathrm{C}_{6}$ (4 20 ) d-spacing of ferritic steel as a function of temperature. Below $800^{\circ} \mathrm{C}$, the crystal lattice expands as a result of the thermal expansion during heating. The thermal expansion coefficient (CTE) for $\mathrm{M}_{23} \mathrm{C}_{6}$ is reported to be $7.9 \times 10-6 / \mathrm{C}$ near room temperature. This value corresponds very well with the experimentally measured CTE value $\left(8.76 \times 10-6 /^{\circ} \mathrm{C}\right)$. The result displays a rapid increase in CTE to a value of $16.4 \times 10-6 /{ }^{\circ} \mathrm{C}$ above $800^{\circ} \mathrm{C}$, which is approximately 1.8 times that observed at lower temperatures. Similarly, the measured CTE value of the $\mathrm{M}_{23} \mathrm{C}_{6}\left(\begin{array}{lll}4 & 2 & 2\end{array}\right)$ is approximately 1.7 times that observed at lower temperatures.

To understand this difference in lattice expansion, the mean crystallite size of $\mathrm{M}_{23} \mathrm{C}_{6}$ carbides is considered as a function of temperature. Figure ${ }^{36}$ ) shows the calculated mean particle size using the integral breadth
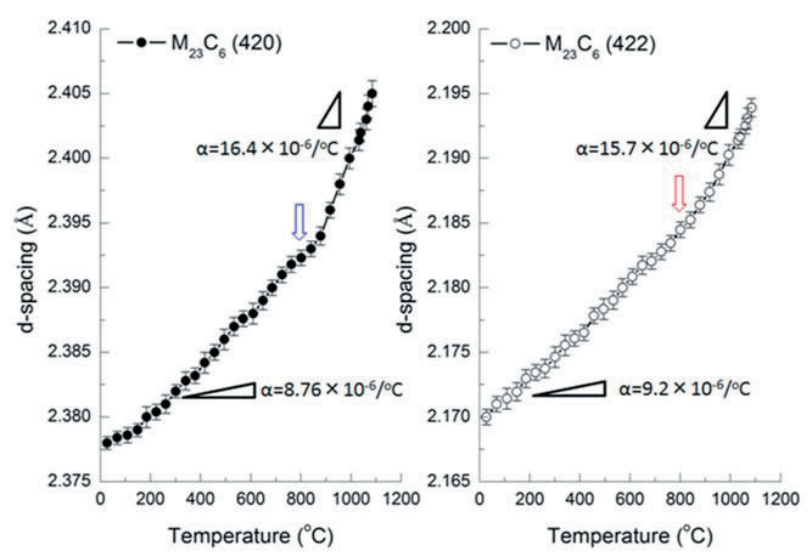

Fig. 6 Tracing the $d$-spacing changes of ( $\left.\begin{array}{lll}4 & 2 & 0\end{array}\right)$ and $\left(\begin{array}{lll}4 & 2 & 2\end{array}\right)$ diffraction peaks of $\mathrm{M}_{23} \mathrm{C}_{6}$ carbides ${ }^{35)}$ 


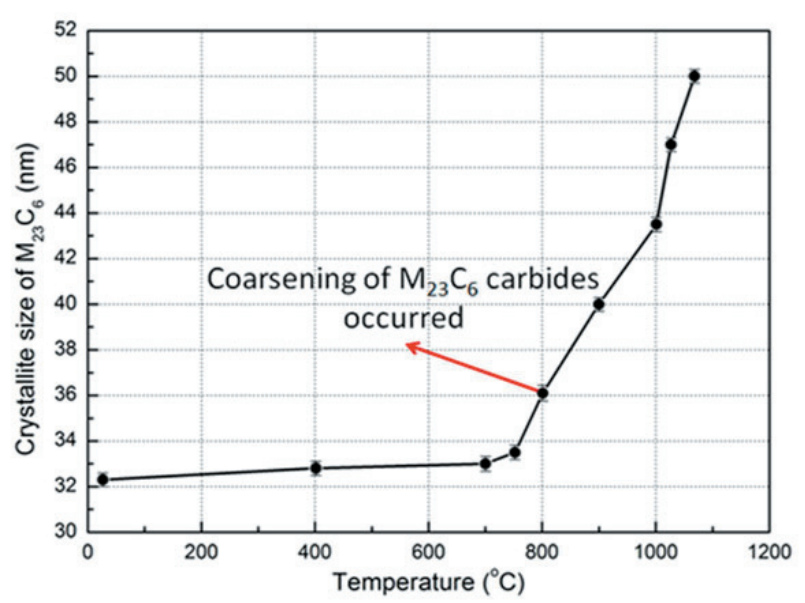

Fig.7 Calculated crystallite size of $\mathrm{M}_{23} \mathrm{C}_{6}$ versus temperature ${ }^{35)}$

method. Above $800^{\circ} \mathrm{C}$, coarsening of $\mathrm{M}_{23} \mathrm{C}_{6}$ carbide particles occurred. The different behaviors before and after $800^{\circ} \mathrm{C}$ are most likely explained by the diffusion of alloying elements. $\mathrm{M}_{23} \mathrm{C}_{6}$ carbides, though generally $\mathrm{Cr}$ rich, can accommodate varying amounts of $\mathrm{Fe}, \mathrm{Mo}$, and $\mathrm{W}$, depending on the temperature and time of formation ${ }^{36}$, 37). It is clear that dislocations are energetically stable for the $\mathrm{M}_{23} \mathrm{C}_{6}$ precipitates, since $\mathrm{Cr}$-rich $\mathrm{M}_{23} \mathrm{C}_{6}$ particles mainly precipitate on prior austenite grain boundaries, ferrite subgrain boundaries and on dislocations inside subgrains. The coarsening of $\mathrm{M}_{23} \mathrm{C}_{6}$ precipitates could possibly be caused by a solute drag effect where substitutional atoms are carried by migrating dislocations. Calculations made by $\mathrm{Hald}^{36)}$ on $9-12 \% \mathrm{Cr}$ steels show that solubility and diffusion of Mo control the coarsening of $\mathrm{M}_{23} \mathrm{C}_{6}$ carbides. Therefore an increased mobility of Mo and $\mathrm{W}$ atoms could contribute to the coarsening of carbides. Although it is generally accepted that $\mathrm{Cr}$ and $\mathrm{Fe}$ are the main elements in $\mathrm{M}_{23} \mathrm{C}_{6}$ carbides, $\mathrm{Mo}$ and $\mathrm{W}$ will also play a role in the coarsening of $\mathrm{M}_{23} \mathrm{C}_{6}$ precipitates. The atomic radii of $\mathrm{Mo}$ and $\mathrm{W}$ are $1.90 \AA$ and $1.93 \AA$, which are larger than the radii of $1.66 \AA$ and $1.56 \AA$ for $\mathrm{Cr}$ and $\mathrm{Fe}$ respectively. Thus, lattice expansion increases markedly during the coarsening of $\mathrm{M}_{23} \mathrm{C}_{6}$ carbides.

\section{Diffusional and displacive transformation behavior in low carbon low alloy steels}

As an observational example for hybrid systems, the phase transformation behaviour of diffusional (mild steel (MS)) and displacive (low-temperature transformation steel (LTT)) transformations were compared with this system. The origin and morphology of the microstructural change were analysed in real space. The d-spacing change was also analysed to assess the carbon partitioning behaviour in the reciprocal lattice space.

An LTT specimen was prepared in order to observe the displacive transformation. The LTT material should reduce the residual stress by using transformation strain in the welding field ${ }^{38)}$. The chemical composition of the LTT was $0.03 \mathrm{C}, 0.07 \mathrm{Si}, 0.09 \mathrm{Mn}$ and $9.88 \mathrm{Ni}$ (mass\%). The chemical composition of the MS was $0.06 \mathrm{C}, 0.4 \mathrm{Si}$,
$1.01 \mathrm{Mn}, 0.01 \mathrm{P}$ and $0.008 \mathrm{~S}$ (mass\%). The specimen was $5.0 \mathrm{~mm}$ in diameter and $2.0 \mathrm{~mm}$ in height, and it was inserted into a boron nitride crucible. Both specimens were subjected to the same thermal cycle, heated up to $1000^{\circ} \mathrm{C}$ and cooled down to room temperature. The time resolution of XRD detection was $0.2 \mathrm{~s}$. The diffraction data were analysed using the method and programming described in Ref. ${ }^{39)}$. On the other hand, the LSCM images were recorded in the time resolution of $0.03 \mathrm{~s}$ throughout the thermal cycle. Figure $8^{32}$ shows snapshots of the LSCM images for the LTT and MS specimens during the cooling cycle. In the case of the LTT, austenite was supercooled to $300^{\circ} \mathrm{C}$, as shown in Figure 8 LTT-(i). Further cooling caused a martensitic transformation, as shown in Figure 8 LTT-(ii) and (iii). The image contrast of the precipitate was very clear because of the surface relief of the martensite. The yield stress increased linearly as the temperature decreased. Then the elastic strain balanced the transformation strain and it was effective in reducing the residual stress in the restricted weld. In the case of the MS, at $640^{\circ} \mathrm{C}$, a very weak contrast was observed on the grain boundary of the austenite and spread throughout the images at $550^{\circ} \mathrm{C}$, as shown in Figure 8 MS-(ii) and (iii). The nucleation site and the morphology of the precipitate were of the nature of a ferrite allotriomorph. The nucleation temperature should be higher than $640^{\circ} \mathrm{C}$ because the magnification of LSCM images is 100 . The image contrast of the ferrite allotriomorph was very weak because there was no relief on the surface of the specimen. The contrast in the LSCM image is affected by two factors: the formation of relief and a difference in reflectivity. In the case of relief

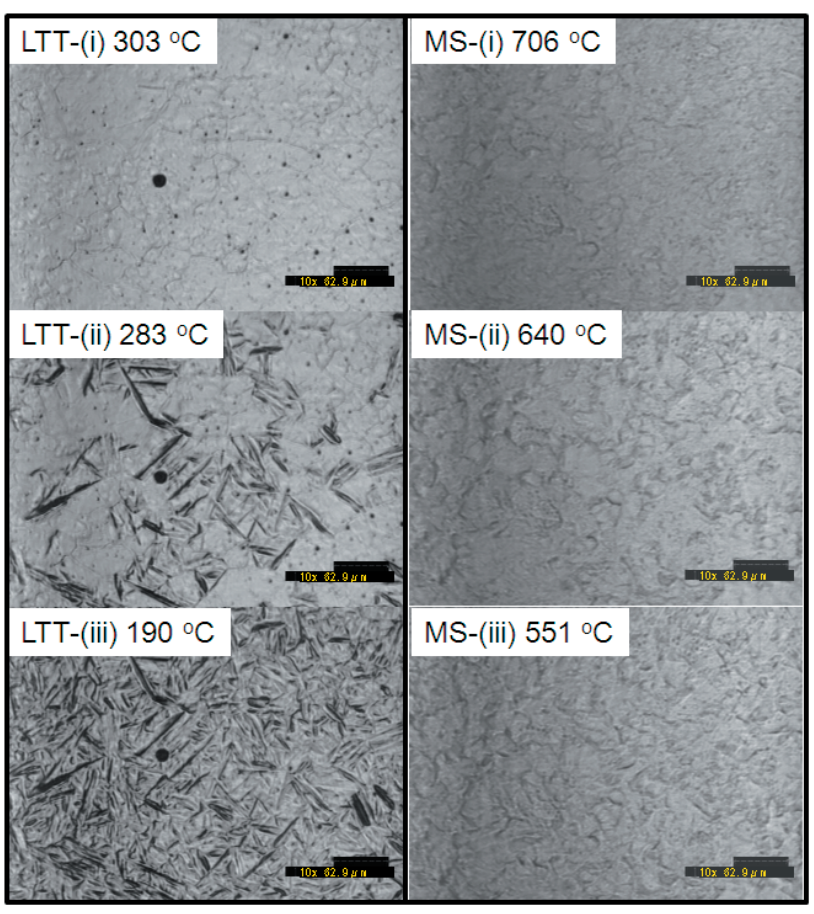

Fig.8 Snapshots of solid-state transformation during the cooling cycle in LTT (LTT-(i), (ii), (iii)) and MS (MS-(i), (ii), (iii)) ${ }^{32)}$ 
formation, such as displacive transformation and thermal grooving at the grain boundary, the difference in the reflection direction of the laser light is responsible for the clear contrast in the LSCM image. On the other hand, in diffusional transformation, the contrast is very weak, as shown in Figure 8. This means that there is no surface relief, and the contrast is due to the differences of reflectivity between the ferrite and austenite. The light reflectivity is governed by the electrical conductivity. The difference of electrical conductivity between the ferrite and austenite should be small in the current chemical composition, and this difference causes a very weak contrast in the case of diffusional transformation. Figure $9^{32)}$ shows the d-spacing, time, temperature and intensity diagram (LTT-(a) and MS-(a)) during the phase transformations in the cooling cycle. The displayed reflection is that of austenite $\left(\begin{array}{lll}1 & 1 & 1\end{array}\right)$ and ferrite $\left(\begin{array}{lll}1 & 1 & 0\end{array}\right)$. The intensity was normalized. In the macro-view, the $\mathrm{d}$-spacing of the austenite and ferrite decreased because of thermal shrinkage in the LTT and MS. When the phase transformation occurred, the intensity of the austenite decreased, as shown in Figure 9. The marks (i), (ii) and (iii) in the temperature profile correspond to the number in Figure 8 for each steel sample. There was a discrepancy of approximately $20 \mathrm{C}$ between the surface temperature of the specimen and the thermocouple set behind the platinum plate stage. This discrepancy suggests that the LSCM images were compatible with the diffraction pattern. Hence, the developed system could follow the phase transformations in both real and reciprocal lattice space. Figure 9 LTT-(b) and MS-(b) show enlarged views of the austenite $\left(\begin{array}{lll}1 & 1 & 1\end{array}\right)$ diffraction peaks when the austenite decreased because of the phase transformations. The d-spacing continuously decreased along the trends in the macro-view in the LTT, whereas it increased against the trends in the MS. In order to analyse this phenomenon, a fit of Gaussian peaks ${ }^{39)}$ to the austenite reflection ( $\left.\begin{array}{lll}1 & 1 & 1\end{array}\right)$ was performed. Figure 4 shows the result of $d$-spacing that was derived using a fit

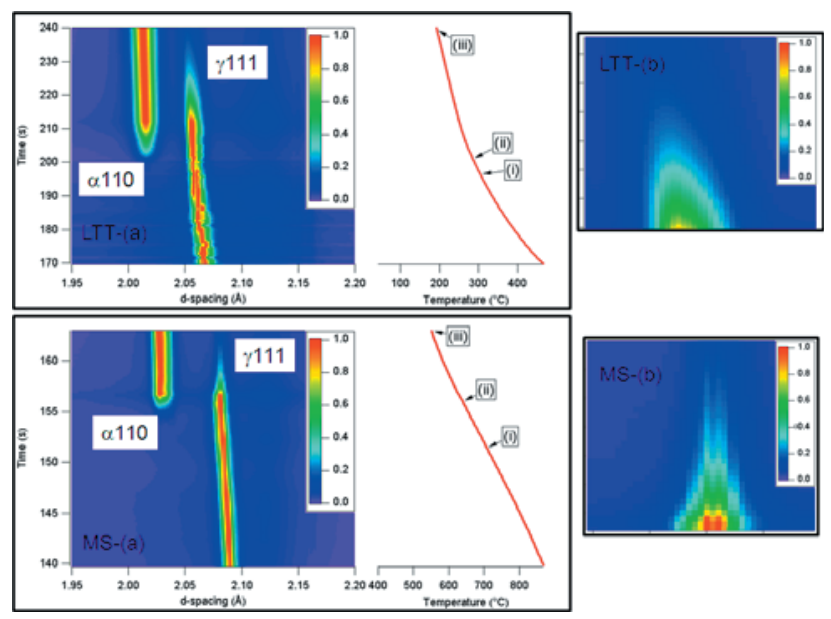

Fig.9 The d-spacing, time and temperature-intensity diagram during the cooling cycle in LTT (LTT-(a)) and MS (MS-(a)) ${ }^{32)}$ of Gaussian peaks in the LTT and MS (shown in the low-temperature and high-temperature region, respectively, in Fig. 4). As expected, in the case of the LTT, the d-spacing continuously decreased along the cooling cycle. On the other hand, in the case of the MS, $\mathrm{d}$-spacing continuously decreased until $643^{\circ} \mathrm{C}$ and then suddenly increased at the point shown in Figure 9 MS-(b) There is a possibility that the inhomogeneous carbon distribution occurred because of the insufficient austenitization and affected the d-spacing change. However, the continuous decreasing of $\mathrm{d}$-spacing prior to phase transformation (as shown in Fig. 10, marked "MS") means the discontinuous change around $643^{\circ} \mathrm{C}$ was due to the phenomena during phase transformation. The discontinuous change in d-spacing is due to the high carbon formation after the phase transformation. Furthermore, there was no splitting behaviour ${ }^{40)}$ in the austenite peaks. Thus, it could be concluded that the carbon partitioning expanded the lattice parameter as observed in the ferrite allotriomorph formation. In the case of the displacive transformation, there was no partitioning of carbon, and the expansion was not observed in the TRXRD data. A large-area detector, Pilatus $2 \mathrm{M}^{19)}$, was installed in the experimental system. Then the austenite reflections of ( $\left.\begin{array}{lll}1 & 1 & 1\end{array}\right),\left(\begin{array}{lll}2 & 0 & 0\end{array}\right),\left(\begin{array}{lll}2 & 2 & 0\end{array}\right)$ and $\left(\begin{array}{lll}3 & 1 & 1\end{array}\right)$ were recorded over time. All the reflections had the same tendency (i.e., increasing d-spacing because of carbon partitioning in MS), and the results were verified statistically. As is clearly observed in Figure 10, the d-spacing change in the MS looks very smooth, whereas that in the LTT looks uneven. Note that the uneven form appeared before phase transformation and was smooth after phase transformation, as shown in the low-temperature region of Figure 10. The major difference in the phase transformation of each austenite is the degree of supercooling. The supercooling may affect crystal stability. Further statistical research is needed to assess the effect from this perspective.

The phase transformation behaviour of mild steel and low-temperature-transformation steel was observed in situ with a developed hybrid TRXRD/LSCM system. When the ferrite allotriomorph was formed in the mild steel, carbon partitioning occurred, and the d-spacing of

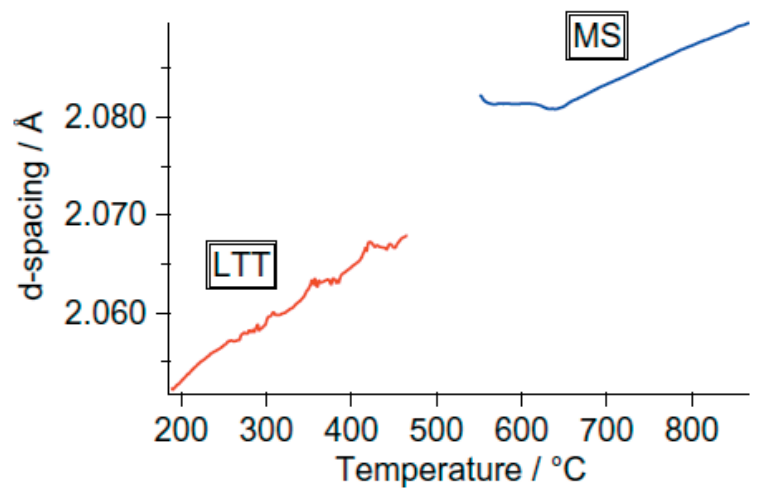

Fig.10 Tracing of the d-spacing change during phase transformations in LTT and MS, derived from the fitting of Gaussian peaks ${ }^{32}$ ) 
the austenite reflection (1 11 1 $),\left(\begin{array}{lll}2 & 0 & 0\end{array}\right),\left(\begin{array}{lll}2 & 2 & 0\end{array}\right)$ and (3 111$)$ increased even when thermal shrinkage occurred during the cooling thermal cycle. Our system should also help to analyse other transformation mechanisms of steel, such as bainite and massive transformations.

\section{Summary}

A new technique, based on the combination of time-resolved X-ray diffraction (TRXRD) and laser scanning confocal microscopy (LSCM), was developed for direct observation of morphological evolution and simultaneous identification of the phases. TRXRD data and LSCM images under the desired thermal cycles were measured simultaneously. As described above, the combination of LSCM and TRXRD is effective in investigating the phase transformation kinetics during thermal cycles of rapid heating and cooling. The system can be applied to the analysis of microstructural changes for improved control of properties in welds.

\section{Future works}

Synchrotron based X-ray diffraction techniques combined with high-temperature laser scanning confocal microscopy; provide new and powerful tools for the study of phase transformations and microstructural evolution during welding.

Detecting a wider area of the Debye circle is very important. Mounting several detectors on the arm of the diffractometer increases the detection range for the part of the Debye circle. Continual improvements in synchrotron based methods can only increase the ability to monitor these transformations at higher spatial and temporal resolutions during welding. When combined with additional experiments and modelling, these techniques enable a deeper understanding of the kinetics of phase transformations.

\section{Acknowledgements}

The synchrotron radiation experiments were performed at the SPring- 8 with the approval of the Japan Synchrotron Radiation Research Institute (JASRI) (Proposal No. 2009B2086 and 2011B1968). The authors are grateful to Dr. Sato and Dr. Toyokawa, JASRI, for profitable discussion.

This study was conducted as a part of research activities of 'Fundamental Studies on Technologies for Steel Materials with Enhanced Strength and Functions' by the Consortium of JRCM (The Japan Research and Development Center of Metals). Financial support from NEDO (New Energy and Industrial Technology Development Organization) is gratefully acknowledged.

\section{References}

1) J.W. Elmer, J. Wong, T. Ressler, Metallurgical and Materials Transactions A. 29 (1998) 2761-2773.

2) J.W. Elmer, J. Wong, T. Ressler, Metallurgical and Materials Transactions A. 32 (2001) 1175-1187.

3) J.W. Elmer, T.A. Palmer, J. Wong, Journal of Applied Physics. 93 (2003) 1941-1947.
4) J.W. Elmer, T.A. Palmer, Metallurgical and Materials Transactions A. 37A (2006) 2171-2182.

5) J.W. Elmer, T.A. Palmer, W. Zhang, B. Wood, T. DebRoy, Acta Materialia. 51 (2003) 3333-3349.

6) W. Zhang, J.W. Elmer, T. DebRoy, Science and Technology of Welding and Joining. 10 (2005) 574-582.

7) J.W. Elmer, J. Wong, T. Ressler, Scripta Materialia. 43 (2000) 751-757.

8) J.W. Elmer, T.A. Palmer, S.S. Babu, W. Zhang, T. DebRoy, Welding Journal. 83 (2004) 244S-253S.

9) J.W. Elmer, T.A. Palmer, S.S. Babu, W. Zhang, T. DebRoy, Journal of Applied Physics. 95 (2004) 8327-8339.

10) S.S. Babu, J.W. Elmer, J.M. Vitek, S.A. David, Acta Materialia. 50 (2002) 4763-4781.

11) T.A. Palmer, J.W. Elmer, S.S. Babu, Materials Science and Engineering a-Structural Materials Properties Microstructure and Processing. 374 (2004) 307-321.

12) J. Wong, T. Ressler, J.W. Elmer, Journal of Synchrotron Radiation. 10 (2003) 154-167.

13) Y. Komizo, T. Osuki, M. Yonemura, H. Terasaki, Transactions of JWRI. 33 (2004) 143-146.

14) T. Osuki, M. Yonemura, K. Ogawa, Y. Komizo, H. Terasaki, Science and Technology of Welding and Joining. 11 (2006) 33-42.

15) Y. Komizo, H. Terasaki, M. Yonemura, T. Osuki, Transactions of JWRI. 34 (2005) 51-55.

16) M. Yonemura, T. Osuki, H. Terasaki, Y. Komizo, M. Sato, A. Kitano, Materials Transactions. 47 (2006) 310-316.

17) H. Terasaki, Y. Komizo, M. Yonemuira, T. Osuki, Metallurgical and Materials Transactions A. 37A (2006) 1261-1266.

18) M. Yonemura, Y. Komizo, H. Toyokawa, SPring 8

Research Frontier (2006) 129-130.

19) M. Yonemura, T. Osuki, H. Terasaki, Y. Komizo, M. Sato, H. Toyokawa, Materials Transactions. 47 (2006) 2292-2298.

20) Y. Komizo, H. Terasaki, Tetsu To Hagane-Journal of the Iron and Steel Institute of Japan. 94 (2008) 1-5.

21) Y. Komizo, Journal of the Japan Welding Society. 77 (2008) 26-31.

22) Y. Komizo, H. Terasaki, M. Yonemura, T. Osuki, Welding in the world-London-. 52 (2008) 56-63.

23) T. Hashimoto, H. Terasaki, Y. Komizo, Science and Technology of Welding and Joining. 13 (2008) 409-414.

24) H. Terasaki, T. Yamada, Y. Komizo, Isij International. 48 (2008) 1752-1757.

25) H. Terasaki, K. Yanagita, Y. Komizo, M. Sato, H.

Toyokawa, Quarterly Journal of The Japan Welding Society. 27 (2009) 118s-121s.

26) D. Zhang, H. Terasaki, Y. Komizo, Journal of Alloys and Compounds. 484 (2009) 929-933.

27) H. Terasaki, Y. Komizo, Science and Technology of Welding and Joining. 11 (2006) 561-566.

28) T. Yamada, H. Terasaki, Y. Komizo, Science and

Technology of Welding and Joining. 13 (2008) 118-125.

29) Y. Komizo, H. Terasaki, Science and Technology of Welding and Joining. 16 (2011) 56-60.

30) Y. Komizo, H. Terasaki, Science and Technology of Welding and Joining. 16 (2011) 61-67.

31) Y. Komizo, H. Terasaki, Science and Technology of Welding and Joining. 16 (2011) 79-86.

32) H. Terasaki, Y. Komizo, Scripta Materialia. 64 (2011) 29-32.

33) B.E. Warren, X-ray diffraction, Courier Dover Publications, 1990

34) X.F. Zhang, H. Terasaki, Y. Komizo, Scripta Materialia. 67 (2012) 201-204 


\section{Hybrid system for in-situ observation of microstructure evolution in steel materials}

35) X.F. Zhang, Y. Komizo, Philosophical Magazine Letters. 93 (2013) 9-17.

36) J. Hald, International Journal of Pressure Vessels and Piping. 85 (2008) 30-37.

37) R. Mythili, V.T. Paul, S. Saroja, A. Vijayalakshmi, V.S. Raghunathan, Journal of Nuclear Materials. 312 (2003) 199-206.

38) S. Zenitani, N. Hayakawa, J. Yamamoto, K. Hiraoka, Y.
Morikage, T. Kubo, K. Yasuda, K. Amano, Science and Technology of Welding and Joining. 12 (2007) 516-522. 39) S.S. Babu, E.D. Specht, S.A. David, E. Karapetrova, P. Zschack, M. Peet, H. Bhadeshia, Metallurgical and Materials Transactions A. 36A (2005) 3281-3289.

40) T.A. Palmer, J.W. Elmer, Scripta Materialia. 53 (2005) 535-540. 